\title{
Chiropractic spinal manipulation did not lead to an improvement in infantile colic or reduce crying
}

\author{
Olafsdottir E, Forshei S, Fluge G, et al. Randomised controlled trial of infantile colic treated with chiropractic spinal \\ manipulation. Arch Dis Child 2001 Feb;84:138-41.

\section{QUESTION: Is chiropractic spinal manipulation effective in the treatment of infantile colic?}

\section{Design}

Randomised \{allocation concealed $\}^{*}$, blinded (paediatrician, parents, and outcome assessor), placebo controlled trial with 8-14 days of follow up.

\section{Setting}

$\{$ Outpatient ward in a paediatric department in Bergen, Norway. $\}^{*}$

\section{Patients}

100 thriving infants (3-9 wks) who cried $\geqslant 3$ hours/day, 3 days/week for the previous 3 weeks with no sign of lactose intolerance, no previous chiropractic treatment, and who were non-responsive to a cows' milk free diet in the mothers who breast fed or to casein hydrolysed formula for those who were bottle fed. The infants were recruited from public health clinics, the paediatric outpatient clinic at the university hospital, general practitioners, chiropractors, and maternity units. 9 infants $(9 \%)$ did not meet the inclusion criteria and were excluded; 5 infants did not complete the trial. Of the 86 who completed the trial, $55 \%$ were boys and the mean birth weight was $3690 \mathrm{~g}$.

\section{Intervention}

46 infants were allocated to spinal manipulation and 40 to the control group. Infants in the spinal manipulation group were brought by a nurse to the chiropractor who used a very light, modified fingertip mobilisation form of spinal manipulation (no joint "cracks"). The treatment was given 3 times, at intervals of 2-5 days, for a period of 8 days. Infants in the control group did not receive spinal manipulation but were held by the nurse for 10 minutes.

\section{Main outcome measures}

The primary outcome was amount of improvement reported by the parent on a 5 point scale. The secondary outcome was amount of crying $(\mathrm{h} / \mathrm{d})$.

\section{Main results}

The groups did not differ for parent reported improvement or for amount of crying time. 32 of 46 infants $(70 \%)$ showed some improvement in the treatment group, whereas 24 of $40(60 \%)$ showed improvement in the control group $(p=0.4)$. Crying time was reduced by a similar amount in the treatment and control groups (treatment group $5.1 \mathrm{~h} / \mathrm{d}$ at baseline to $3.1 \mathrm{~h} / \mathrm{d}$ at follow up $v$ control group $5.4 \mathrm{~h} / \mathrm{d}$ at baseline to $3.1 \mathrm{~h} / \mathrm{d}$, $\mathrm{p}=0.98)$.

\section{Conclusion}

Chiropractic spinal manipulation did not lead to an improvement in infantile colic or reduce infants' crying time.

*Information provided by author.

\section{COMMENTARY — continued from previous page}

The study sample size was much smaller than anticipated: over a 2 year period, 38 completed the trial although the anticipated sample size was 150 . This speaks to the challenges of recruitment, particularly when there is a strict definition of colic and a measurement instrument to be completed by parents who are already overburdened with coping with a colicky infant. The high average crying time in recruited infants may be related to their parents' motivation to enter the study. With such a small number of infants in the trial, it is not surprising that the treatment and control groups differed in age, sex, crying and crying/fussing levels, and the presence of a food allergy at baseline. As a result, we must rely on the adjusted analysis which just achieves statistical significance with a $p$ value of 0.05 .

The findings from these 2 studies have important implications for nurses in clinical practice and research. When providing anticipatory guidance to prospective parents, and when counselling parents of newborns about infant crying, nurses need to present parents with realistic expectations, common causes, and practical relief measures. If crying is consistently in excess of 3 hours/day, then a detailed assessment is required. Other disorders need to be ruled out. Reassurance, teaching, counselling, and support always should be the first intervention measures. The evidence from these studies supports a switch from cows' milk formula to whey hydrolysate formula in formula fed infants with colic, but not the use of spinal manipulation. Nurses have an important part to play in educating new parents and other health professionals in this area.

This evidence highlights the continuing need for research on the causes of infantile colic and the effectiveness of dietary and alternative treatments, particularly with the increasing interest in complementary medicine. Attention must be paid to the role of breast feeding with any dietary interventions. Studies need to replicate the strong methodology here, with sufficient sample size, placebo control, and blinding. The influence of social factors on colic is another potential area of research. Nurses have a responsibility to advocate for, and participate in, rigorous studies on infantile colic, and to disseminate their findings.

Mary Lou Walker, RN, MHSc Family Health Program Manager, Toronto Public Health Toronto, Ontario, Canada

1 Wessel MA, Cobb JC, Jackson EB, et al. Paroxysmal fussing in infancy, sometimes called "colic." Pediatrics 1954;14:421-34.

2 Lucassen PL, Assendelft WJ, Gubbels JW, et al. Effectiveness of treatments for infantile colic: systematic review. BMJ 1998;316:1563-9.

\footnotetext{
Source of funding: Norwegian Research Council.

For correspondence: Dr E Olafsdottir, Department of Paediatrics, University of Bergen, 5021 Bergen, Norway. Fax +47559 75159 .
} 